\title{
How to Maximize the Success of Stem Cell Autografts for Neuroregeneration
}

\section{Nassim H Abi Chahine ${ }^{1 *}$, Elie S Abou Saad ${ }^{2}$ and Saade Gibran E Melki ${ }^{3}$}

${ }^{1}$ Neurological Surgery, The Lebanese-Canadian Hospital, Beirut, Lebanon, M.D from University of Balamand, Lebanon and The Medical University of Lodz, Poland ${ }^{2}$ Doctor of Pharmacy, , Biologist from Saint Joseph University, Lebanon

${ }^{3}$ Bachelor of Biotechnology and cell biology, biologist from Latrobe University, Monash, Australia

\begin{abstract}
Over a period of five years, two hundred patients with degenerative chronic neurological disorders were monitored after the treatment with adult autologous bone marrow derived stem cells. Our field of study covered a wide range of diseases and multiple protocols were explored. Autologous bone marrow derived stem cells were outsourcing all the procedures. Several steps forward have been achieved. We notably worked on the grounding of patients, stem cells proliferation and processing. We described the decant effect, the ultimate incubation modes, the optimal way of filtration and the active homing phenomena related to cytokines released from the injured zone. We also worked on the techniques of transplantation during the injections. Furthermore this article talks about The First Show Phenomenon and many other symptoms facilitating the understanding of autologous stem cell treatments. Our field of study also covered stem cells clustering, the antibiotic effect on newly transplanted cells, and the implication of Mannitol in neuroregeneration, the role of detoxification before ASCT (Autologous stem cell transplantation) in Amyotrophic lateral sclerosis (ALS), the effect of Jugular treatment before ASCT in Multiple Sclerosis. This article promises big changes in many cardinal steps: The importance of ASCT in spinal cord injuries, the role of hyperbaric chamber and adrenal regeneration. We will finally present our work in the field of nanomedicine with its peptides as a supportive tool in order to strengthen the success of our treatment.
\end{abstract}

We concluded that Time is after-all, the crucial element that defines the percentage of success; it is the superlative condition for regeneration. Patients treated early showed firmly better improvement.

Keywords: Adult bone marrow stem cells; Transplantation; neuroregeneration; Progenitor autografts; Neurodegenerative diseases

\section{Research Background}

When stem cell autograft are referenced in this paper, it is in regards to treating a disease with the patient's own progenitor cells. With the isolation of stem cells capable of self-renewing, proliferation and differentiation into many other cell types, new perspectives in the regeneration of damaged neural tissues are born. It became evident after detailed observation and intensive stem cells therapy research that this area holds enormous potential to transform current medicine, providing treatment for hundreds of incurable diseases. This was only possible after diligent work in adult autologous bone marrow derived stem cell transplantation.

\section{Introduction}

In the last few years, autologous stem cells raised many perspectives to treat refractory diseases which do not respond to conventional therapies. This was enhanced by evidence on in vitro generation of various cell lines. Adult stem cells are present in almost all tissues of the body. Because of their potency, they provide an integrated long term restructuration of the altered immunity system and the biological disorder.

The aim of this research is to study the parameters of success of a stem cells autograft in neuroregeneration. It exposes prosperous results obtained after the treatment of two hundred patients with various diseases in neurology using autologous stem cell derived from the bone marrow.

\section{Materials and Methods}

4833 patients were screened for a period of 5 years, 784 of them were eligible to including criteria and 200 declared their determination and underwent the treatment with autologous stem cells. All Patients signed an informed consent after detailed discussion. The medium length of the preoperative discussion and explanation was 2 hours. Subjects enrolled in this study belonged to many categories and were subjected to various randomized protocols.

All patients were treated with their own bone marrow derived stem cells after being divided into 4 groups: A, B, C and D (Table 1).

A- Patients treated without pre-transplant preparation or posttransplant treatment.

B- Patients treated with pre-transplant preparation.

C- Patients treated without pre-transplant preparation but with post-transplant treatment.

D- Patients treated with pre-transplant preparation and posttransplant treatment.

The following neurological diseases were treated:

*Corresponding author: Nassim Abi Chahine, Neurological Surgery, The Lebanese-Canadian Hospital, Beirut, Lebanon, from University of Balamand, Lebanon and The Medical University of Lodz, Poland, Tel: 009613082498; E-mail: nassim@wp.eu

Received December 11, 2014; Accepted March 13, 2015; Published March 15 2015

Citation: Abi Chahine NH, Abou Saad ES, Melki SGE (2015) How to Maximize the Success of Stem Cell Autografts for Neuroregeneration. J Stem Cell Res Ther 5 : 271. doi:10.4172/2157-7633.1000271

Copyright: (c) 2015 Abi Chahine $\mathrm{NH}$, et al. This is an open-access article distributed under the terms of the Creative Commons Attribution License, which permits unrestricted use, distribution, and reproduction in any medium, provided the original author and source are credited. 


\begin{tabular}{|c|c|c|c|} 
Patients' Category & $\begin{array}{c}\text { Pre-transplant } \\
\text { tuition }\end{array}$ & & $\begin{array}{c}\text { Post-transplant } \\
\text { tuition }\end{array}$ \\
\cline { 1 - 2 } A (control Group A) & No & Transplantation & No \\
\cline { 1 - 1 } B (control Group B) & Yes & No \\
\hline C (control Group C) & No & & Yes \\
\hline D & Yes & & Yes \\
\hline
\end{tabular}

Table 1: Patients repartition according to the adequate regimen; Control Group is when patients lack tuition.

Multiple sclerosis, stroke, dementia, Parkinson's disease, cerebral palsy, autism, spinal cord injury and amyotrophic lateral sclerosis (Table 2).

\begin{tabular}{|c|c|c|c|}
\hline Type of Disease & $\begin{array}{c}\text { Number of patients } \\
(\text { Total }=200)\end{array}$ & & Subtype \\
\hline Multiple Sclerosis & 52 & $\begin{array}{l}24 \\
11 \\
17\end{array}$ & $\begin{array}{l}\text { RRMS } \\
\text { SPMS } \\
\text { PPMS }\end{array}$ \\
\hline Stroke & 23 & $\begin{array}{c}19 \\
4\end{array}$ & $\begin{array}{c}\text { Ischemic } \\
\text { Hemorrhagic }\end{array}$ \\
\hline Dementia & 18 & $\begin{array}{c}5 \\
13\end{array}$ & $\begin{array}{l}\text { Vascular Dementia } \\
\text { Alzheimer }\end{array}$ \\
\hline Parkinson disease & 15 & $\begin{array}{c}10 \\
3 \\
2\end{array}$ & $\begin{array}{c}\text { Tremor-dominant } \\
\text { Akinetic-dominant } \\
\text { Mixed }\end{array}$ \\
\hline Cerebral Palsy & 38 & $\begin{array}{c}31 \\
7\end{array}$ & $\begin{array}{l}\text { Spastic } \\
\text { Ataxic }\end{array}$ \\
\hline Autism & 16 & $\begin{array}{l}9 \\
4 \\
3\end{array}$ & $\begin{array}{c}\text { Classic Autism } \\
\text { Asperger Syndrome } \\
\text { Pervasive Dvlp. Dsdr. }\end{array}$ \\
\hline Spinal cord injury & 19 & $\begin{array}{c}14 \\
5\end{array}$ & $\begin{array}{l}\text { Myelopathy } \\
\text { Axonopathy }\end{array}$ \\
\hline $\begin{array}{l}\text { Amyotrophic Lateral } \\
\text { Sclerosis }\end{array}$ & 19 & $\begin{array}{c}10 \\
3 \\
4 \\
2\end{array}$ & $\begin{array}{l}\text { Classical } \\
\text { PLS } \\
\text { PBP } \\
\text { PMA }\end{array}$ \\
\hline
\end{tabular}

RRMS: Relapsing-Remitting Multiple sclerosis; SPMS: Secondary Progressive Multiple Sclerosis; PPMS: Primary Progressive Multiple Sclerosis; PLS: Primary Lateral Sclerosis; PBP: Progressive Bulbar Palsy; PMA: Progressive Muscular Atrophy

Table 2: Patients distribution according to each neurological disease.

Patients were subjected to all or to selected steps of the following procedure which we named "The Regentime procedure". This procedure is based on the transplantation of adult autologous bone marrow derived progenitor cells involving in vivo and in vitro proliferation. It comprises 5 stages and each stage includes many steps. Regentime consists of a post-transplantation essential treatment.

Regentime procedure stages:

1. The Pre-lab stage
2. The Bone marrow collection stage

3. The Laboratory stage

4. The Transplantation stage

5. The Post-transplantation stage

\section{The pre-lab stage}

Examination: Patients underwent a meticulous interview process investigating the history of the first symptoms of the neurological damage. In this early phase, 2 or more trained and specialized doctors in the field of ASCT were present to evaluate and plan each case.

Patients went through physical examination, to assess the severity of their pathology. Levels and degrees of disease were measured according to adequate scales. In addition laboratory samples were taken in order to perform a full tailored biological, chemical, cytological and histological examination, based on the initial disease.

Premedication: Depending on the neurological disease, patients were given tailored medication protocols. Neurostimulators, neuroprotectors, neurorestorators, neuromodulators, and neuroplasticity or neurogenesis enhancers are the main classes of drugs used before the transplantation procedure. Some particular cases required specific protocols such as the Neutrophils proliferation protocol where patients were subjected to subcutaneous injections of Filgrastim, $10 \mu \mathrm{g} / \mathrm{Kg}$ for 1 to 3 days, or/and the Erythrocytes proliferation protocol with a subcutaneous injections of Erythropoetin, $100 \mathrm{U} / \mathrm{Kg}$ for 1 to 3 days.

\section{Bone marrow collection stage}

The bone marrow puncture site is well planned. We named 3 sites for aspiration: sacrum, posterior and anterior iliac crest. As for bone marrow collection containers; 1 of 3 types of syringes was used: syringes with Heparin coated walls or Heparin coated plastic balls or manually filled syringes with heparin solution $(5000 \mathrm{U} / \mathrm{ml}$, in a proportion of $1 / 10$ of the volume of the collected bone marrow). Aspiration cannulas were in two calibers; either $1.5 \mathrm{~mm}$ or $2.0 \mathrm{~mm}$ (Figure 1).

The aspirate was transferred to the specialized laboratory in heparinized tubes or in transfusion bags containing sodium citrate. The bone marrow aspiration volume was limited to $3 \mathrm{ml} / \mathrm{kg}$ body weight, to prevent potential anemia.

\section{Laboratory stage}

Bone marrow processing: Bone marrow aspirate was collected in centrifuge containers and classical centrifugation was done at $2500 \times$ g for 10 minutes at $20^{\circ} \mathrm{C}$ (Figure 2). The Buffy coat layer was carefully
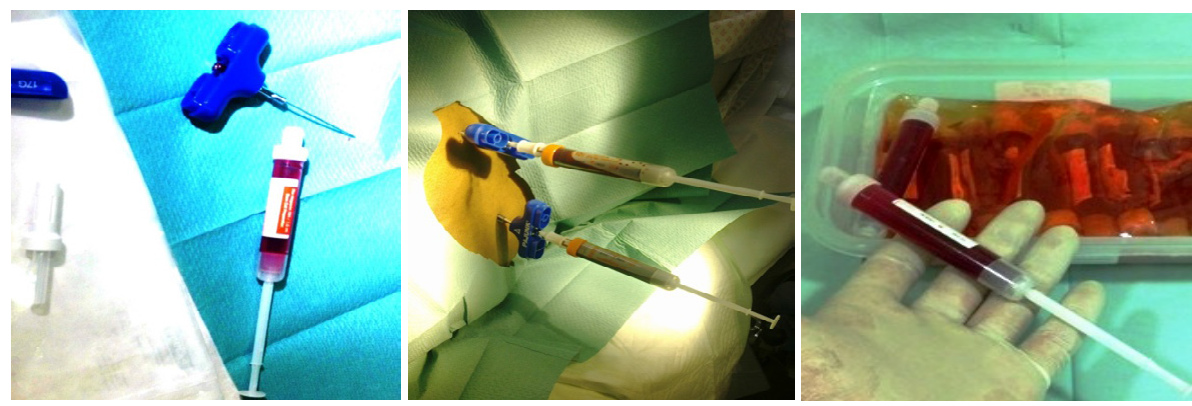

Figure 1: The bone marrow collection kit with heparin coated walls and the aspiration cannula. 

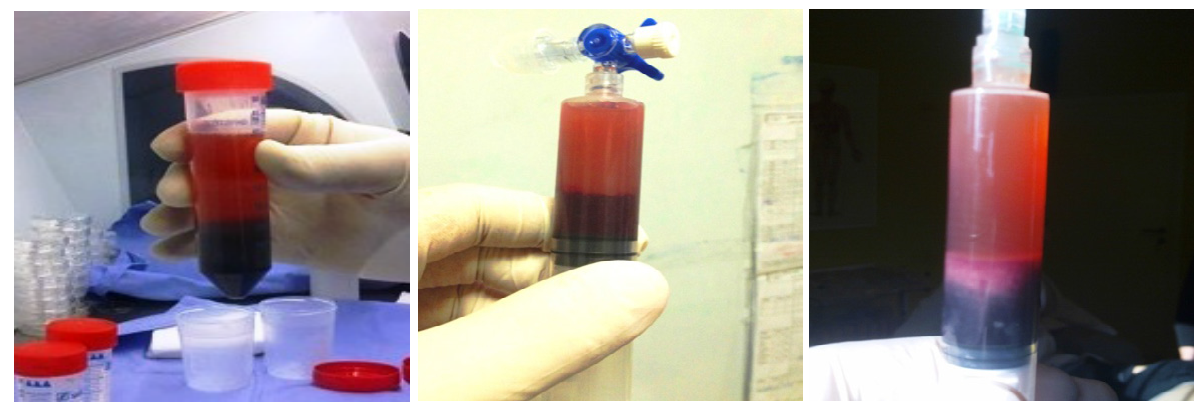

Figure 2: Multiple laboratory work end-steps showing different layers of the bone marrow after its centrifugation.

extracted and it was mixed with human or xeno ultrafiltrates along with tailored proportion of own plasma and/or red blood cells. A mononuclear Cell count was made and clearance for further step was taken when the concentration of mononuclear cells was between 50,000 and $500,000 / \mu l$.

The total number of collected mononuclear cells was estimated to be between $1 \times 10^{9}$ and $3 \times 10^{9}$. This number was considered enough to continue the procedure.

Stem cells incubation: It was made in vitro in 3 ways; either in low temperature $\left(4-8^{\circ} \mathrm{C}\right)$, in room temperature $\left(20-24^{\circ} \mathrm{C}\right)$ or in incubators $\left(37^{\circ} \mathrm{C}\right)$ and we defined 3 different periods of incubation (short: $2-3 \mathrm{~h}$, medium: 10-12 h, long: $24 \mathrm{~h}$ ).

Stem cells were held for hours before transplantation in readyto-use syringes, and they were maintained under continuous shaking (Figure 3).

\section{Transplantation stage}

Stem cells injections were handed by a trained laboratory personal in hermetically closed plastic containers inside thermostatic bags to protect cells from any possible contamination, excessive temperature changes or even solar light.

Stem cells were transplanted via specific routes:

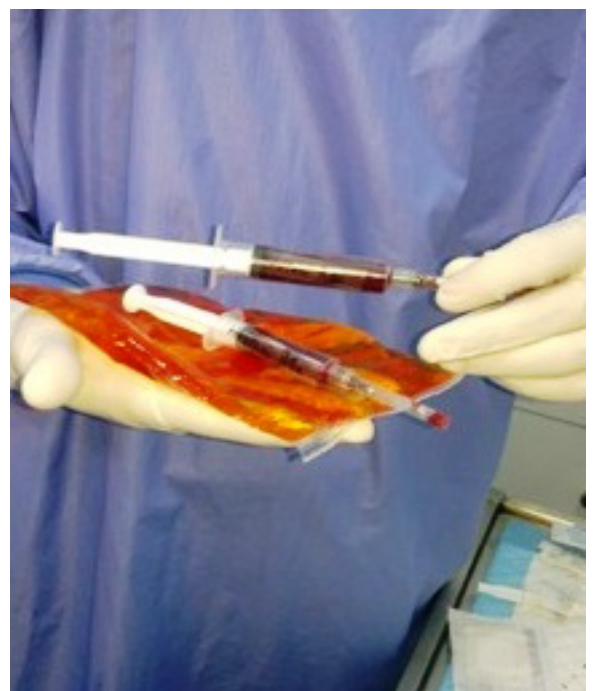

Figure 3: Intrathecal and intravenous doses of bone marrow derived stem cells in ready-to-use syringes.

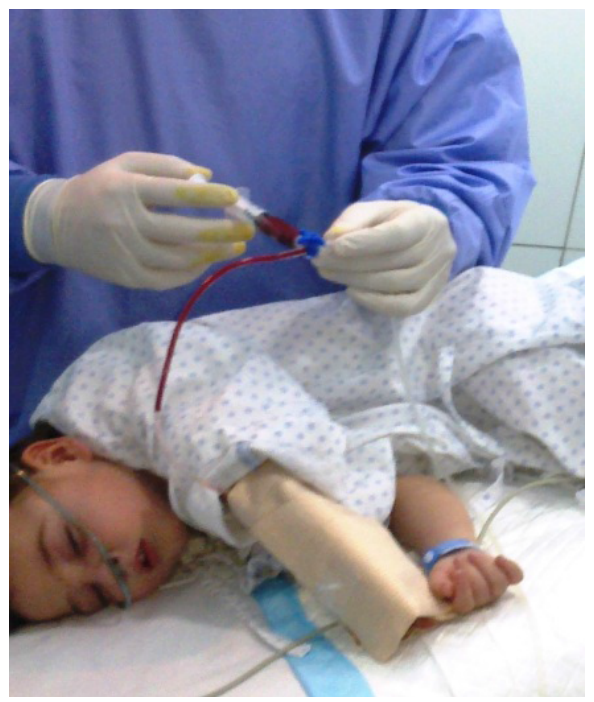

Figure 4: An intravenous autologous stem cell infusion in a 1 year old boy with a brain hypoxic event.

- Intrathecal instillation

- Intravenous infusion

Intrathecal injection: Classical lumbar puncture was made. Cerebrospinal fluid in a quantity of $70 \%$ of the injected volume of cells was slowly drained or actively aspired via a lumbar puncture needle (Size 21-22 G for adult and $23 \mathrm{G}$ for children) and replaced by the intrathecal injection of stem cells.

Intravenous infusion: Patients were given a bolus dose of Mannitol (20\%) 30 minutes before the intravenous injection then stem cells were given via rapid intravenous infusion; i.v. push (Figure 4).

\section{Other methods of direct stem cells transplantation are:}

- The implantation of gel foam with stem cells (Figure 5).

- The instillation of stem cell Neurogel made from the patient's own bone marrow plasma in surgically exposed injured spinal cord (Figure 6).

- The direct CT-guided stem cell injections.

\section{Post-transplantation stage}

Patients stayed in Trendelenburg position for 1, 3 or 10 hours. After their discharge, patients were treated with appropriate medication regimen and rehabilitation techniques. 

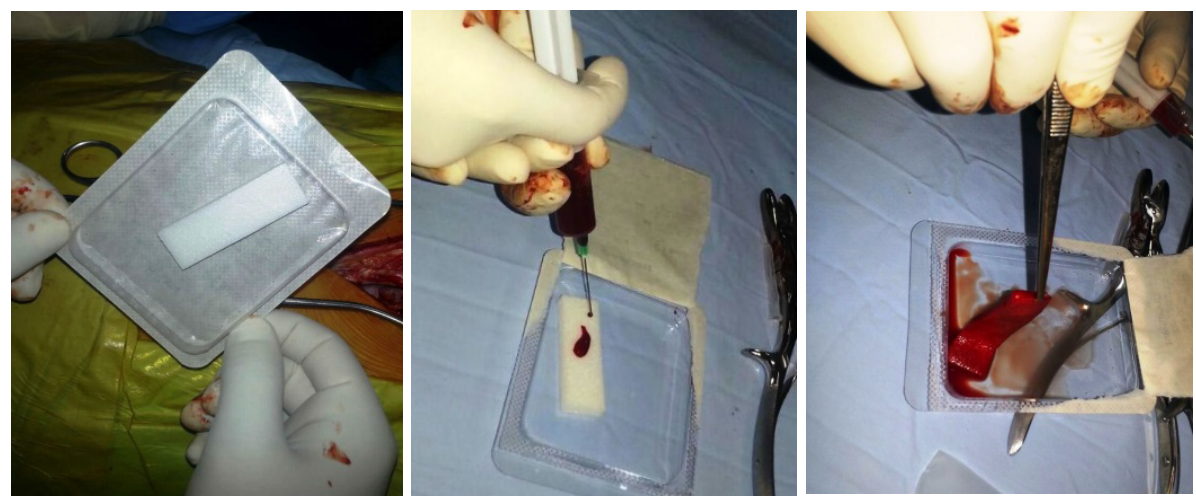

Figure 5: Surgical gel foam saturated with stem cell could be implanted even sub-durally.
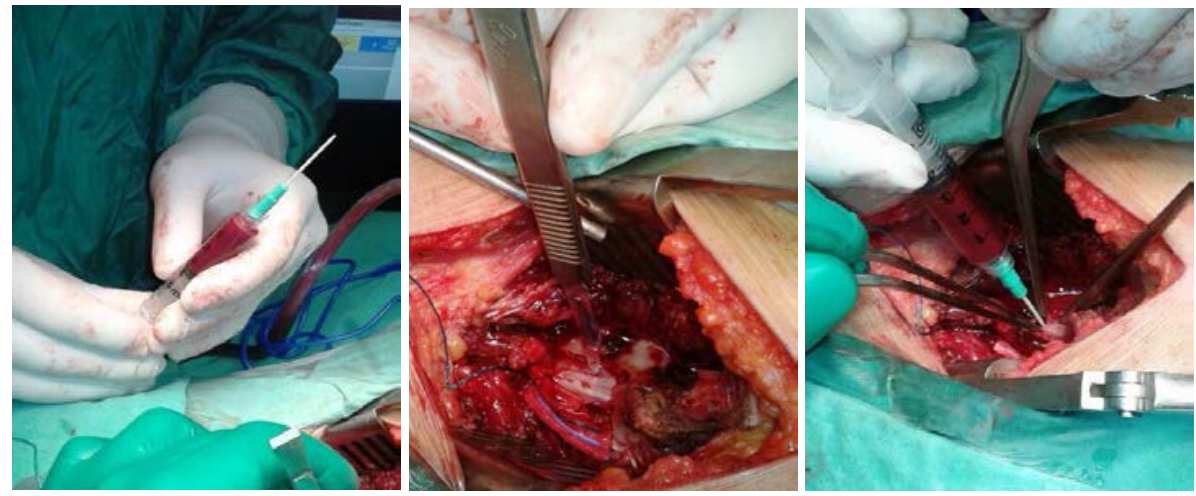

Figure 6: Injection under direct vision of an especially made thick stem cell solution after the dura matter opening.

Assessments were realized at an interval of 1 month for the first 9 months, then every 3 months (Table 3 ).

\section{Results}

\section{Clinical outcomes}

It was noticed that the group of patients who had a pre- and posttransplantation care (preparation and treatment) presented an overall improvement at the level of final results in around 70 to $80 \%$ of cases. Patients receiving premedication for a medium period of 5-7 days prior to the transplantation showed similar results to those who received premedication for longer periods ( 2 weeks and 3 weeks). In some categories, postponing the transplantation at the cost of premedication led to a decrease in the benefits of the procedure.

\section{Stroke}

23 patients with previous brain infarct at different periods were treated with ASCT. All patients had magnetic resonance imaging before treatment and at intervals up to 1 year after. After treatment, there were no signs of venous thrombosis, tumors, central nervous system infections or emerging neurological deficiencies. All patients experienced less spasticity, better coordination and balance, a reduction of the numbness in the legs, arms and face and an amelioration of the speech and the verbal communication. The followup modified ranking scale score ( $\mathrm{p}=0.072,0.161$, and 0.285 at 3,6 , and 12 months, respectively) and the Barthel index ( $p=0.01,0.016$, and 0.114 at 3,6 , and 12 months, respectively) were ameliorated in 14 patients (Figure 7).

\section{Cerebral palsy}

38 Cerebral palsy patients were treated with ASCT. No adverse events or complications were noted. A significant acceleration of the motor function during the first month after transplantation was observed. This improvement was maintained after one year. Cognition, fine motor and gross motor functions were increased in all patients. GMFM-88 and GMFM-66 were significantly increased at 3, 6 and 12 months after ASCT compared with the baseline value (in children). The gross motor function score was significantly ameliorated at the third month (the increase was $36.6, \mathrm{P}=0.001$ ) and at the sixth month (the increase was $37.4, \mathrm{P}=0.001$ ) after treatment. Language quotients were slightly enhanced 3 month after ASCT. Vision and EEG study were markedly improved in related cases (Figure 8).

\section{Amyotrophic lateral sclerosis}

19 patients were treated intravenously or/and via lumbar puncture by bone marrow derived stem cells. MRI showed neither abnormal structural formation nor cell proliferation. The follow up was carried for 2 years after the transplantation. A modest clinical improvement was affirmed on the level of speech, muscle weakness, swallowing and breathing. The revised amyotrophic lateral sclerosis functional rating scale (ALSFRS-R), the hand-held dynamometry (HHD) and the electrical impedance myography (EIM) measurements showed a non-significant improvement during the follow-up period. However, there was no evidence of disease acceleration. Symptoms like cough, dysphagia, pathological laugh and some motor weakness were improved for different periods' length. Improving patients were very willing to repeat the same treatment. 
Citation: Abi Chahine NH, Abou Saad ES, Melki SGE (2015) How to Maximize the Success of Stem Cell Autografts for Neuroregeneration. J Stem Cell Res Ther 5: 271. doi:10.4172/2157-7633.1000271

Page 5 of 10

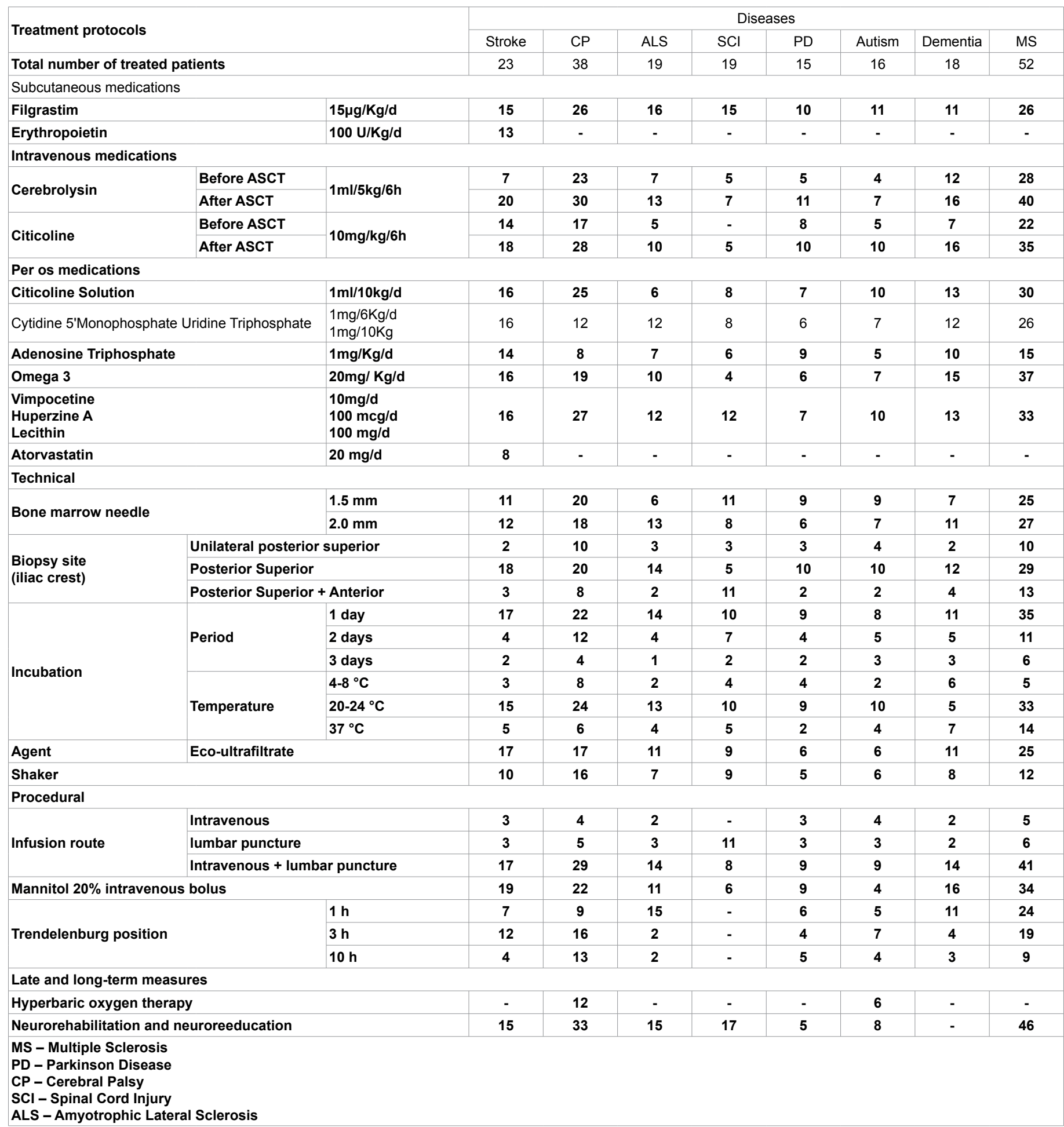

Table 3: Variety of treatment protocols applied to all categories of patients.

\section{Spinal cord injury}

Spinal cord injury can be classified in 2 categories: Myelopathy and Axonopathy.

Based on the severity of the injury, we divided myelopathy into 3 groups: mild (undetectable on MRI), moderate (low hypersignal on T2) and severe (high hypersignal on T2). Each group is defined by the level of the demyelinisation: class A (only one disc space), class B (two disc spaces), and class $\mathrm{C}$ (three disc spaces and more).

14 Myelopahy and 5 axonpathy cases were treated. Patients underwent ASCT with a neurohabilitation program. After three month of follow up, only 6 myelopathy patients showed amelioration on the motor scale presenting better muscle coordination, sensory response and urinary sphincter control erection recovery was noted in 3 cases. 
A
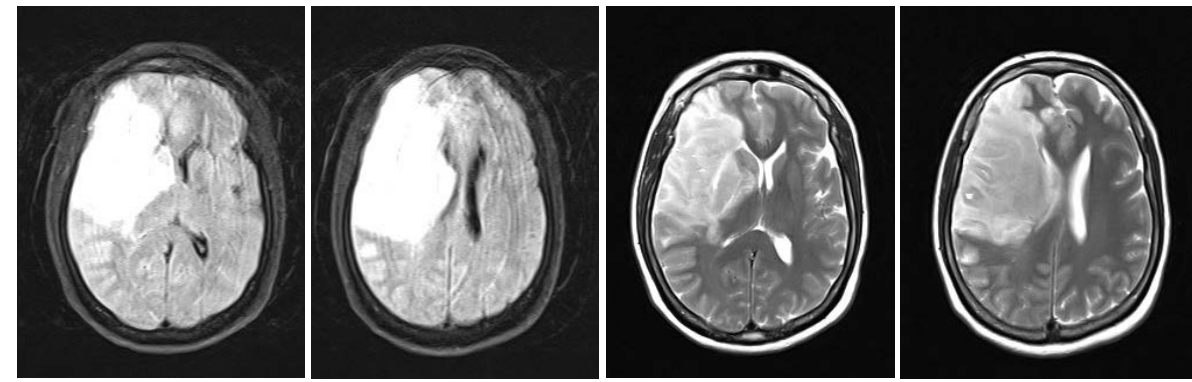

Before Treatment, 1 week after stroke
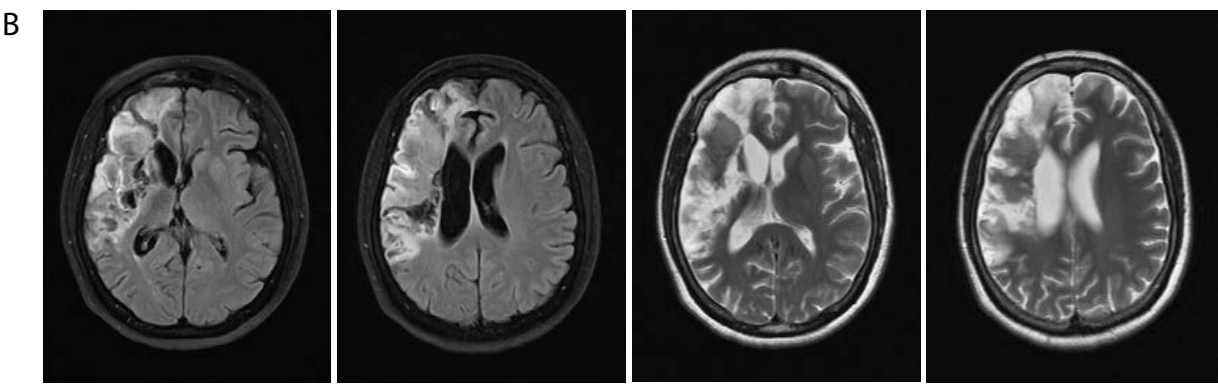

6 months after treatment

C

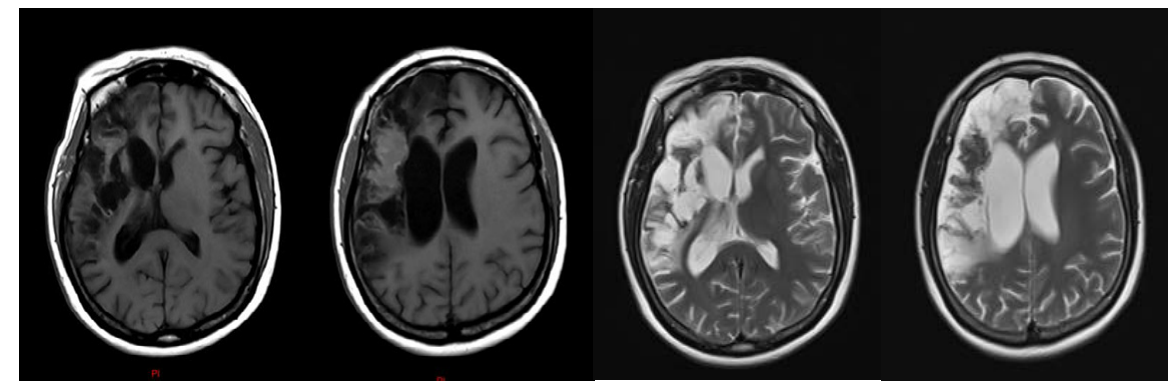

Figure 7: T1 (to the left) and T2 (to the right) MRI sequences of a 52 year old woman with right MCA ischemic stroke before therapy (row a), treated at day 12 after the stroke; 6 months after the therapy (row b) and 12 months after the therapy (row c). See the radiological improvement.

No adverse events were encountered.

\section{Parkinson}

All 15 patients tolerated well the procedure. No major side effects were reported. After 6 months of extensive follow up, 9 patients experienced significant improvement in the daily living activities and an amelioration of the UDPR Scale. Depression and quality of life were notably alleviated. Clinical response was at its peak 12 to 14 months after transplantation and it gradually reached a plateau after 36 months of the baseline. 7 patients had decreased the dosage of their antiParkinson drugs.

\section{Autism}

16 children were treated with bone marrow derived progenitor cells. After 3 months, the behaviours and the learning capacities were improved as it was noticed on the vineland adaptive behaviour scale. 12 children showed better social interaction, verbal and non-verbal communication. The autism diagnostic observation schedule (ADOS) and the clinical global impression (CGI) were ameliorated in 10 patients.

\section{Dementia}

15 of 18 dementia patients showed improvement from the baseline on the Alzheimer's disease Assessment Scale- cognitive at 3 months post transplantation. Cognition, memory and daily living activities were significantly ameliorated. The caregiver-administered neuropsychiatric inventory (CGA-NPI) was used to assess neuropsychiatric symptoms and showed a firm amelioration.

\section{Multiple sclerosis}

33 from 52 treated patients responded positively to the treatment. $60 \%$ improved by at least 0.5 point on the Expanded Disability Status Scale (baseline EDSS $\geq 5$ ). Daily activities were ameliorated especially during the morning period. Itchiness, bladder and vision problems, dizziness, limb spasm and tingling were reduced. 14 patients showed no improvement but remained stable and 5 patients had a disease progression. MS patients who underwent jugular ballooning prior to ASCT didn't show a reduction in the progression of the disease comparing to the group who didn't undergo this procedure.

\section{Discussion}

This present research is focused on the use of adult autologous bone marrow derived stem cells in neuroregeneration.

Beside popular hematopoietic-lineage stem cells, pluripotent stem cells reported in the bone marrow are the following: MAPCs, MACS, 

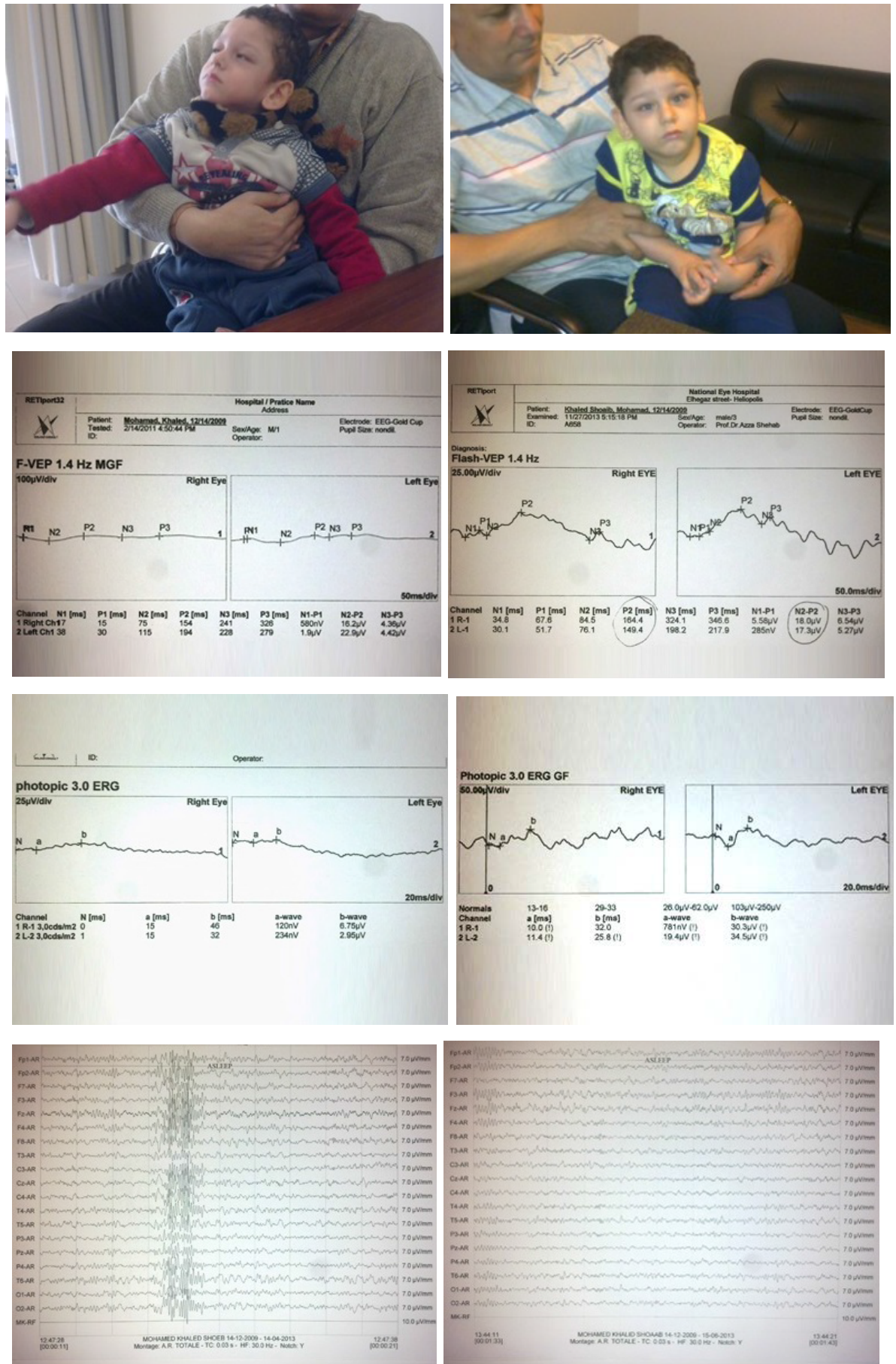

Figure 8: A 3 year old cerebral palsy hypotonic child (Left column) with congenital blindness and multidrug resistant epilepsy, seen 12 months after the bone marrow derived stem cell therapy (right column). He has better motor function, coordination and detectable vision on all retinal studies. He is free from epilepsy.

\begin{tabular}{|c|c|}
\hline MAPCs & Multipotent Adult Progenitor Cells [1] \\
\hline MACS & Multipotent Adult Cells [2] \\
\hline MIAMI & Marrow Isolated Adult Lineage Inducible Cells [3] \\
\hline MPCs & Mesodermal Progenitor Stem Cells [4] \\
\hline VSELs & Very Small Embryonic-like Stem Cells [5] \\
\hline
\end{tabular}

Table 4: Types of Stem Cells used in the study.
MIAMI, MPCs and VSELs (Table 4), they are all found as mononuclear cells.

This paper demonstrates that bone marrow derived progenitor cells can efficiently help in treating the neurological damage and we demonstrated as well the security of their use in human after careful technical measures, achieving the ultimate outcomes in every step of the ASCT procedure. 
A series of actions and measures was taken before, during and after the transplantation. Stem cells have a tendency to migrate toward hypoxic and inflammatory areas which define damaged organs so any possible inflammation should be treated before undergoing the transplantation (Table 5).

Firstly, work was done establishing grounding; Patients' proper preparation was crucial to ensure a superlative environment for stem cells proliferation and survival prior to transplantation.

In order to achieve the best results and to have the highest concentration of progenitor cells at the target region; concomitant infections were eradicated before the transplantation.

In case of inflammations corticosteroids are preferred over Nonsteroidal anti-inflammatory drug. On one hand they have an antiinflammatory effect needed to decrease the chemotactic effect of the inflamed spot and on the other hand, they suppress the immunity mediated by $\mathrm{T}$ and $\mathrm{B}$ cells which is fundamental in auto-immune diseases.

Heavy metal intoxication is another issue to be dealt with (Table 6). Extensive detoxifying regimen and specific chelating agents are required to enhance the survival of the grafted cells and to prevent future damage.

The effect of Filgrastim was described, in elevating bone marrow cellularity and inducing the mobilization of endogenous stem cells [1-7]. The Filgrastim group showed firmly better clinical outcomes. In regular adult responders to Filgrastim, an initial number of approximately $1 \times 10^{9}$ Stem Cells was collected. A lower number of cells seem to be less effective in offering a noticeable change in all type of studied diseases. Only two "slow responders" were found between 130 patients subjected to this drug.

\begin{tabular}{|c|c|}
\hline Active infections being treated & Number of treated patients (Total: 19 cases) \\
\hline Urogenital & 3 \\
\hline Orobuccal & 4 \\
\hline Wound & 8 \\
\hline Respiratory tract & 4 \\
\hline
\end{tabular}

Table 5: Number of treated patients for any active infection before ASCT.

\begin{tabular}{|c|c|}
\hline Heavy metal & $\begin{array}{c}\text { Chelating agent } \\
\text { Aluminum }\end{array}$ \\
\hline Arsenic & Deferoxaine (Desferal) \\
\hline Mercury & \\
\hline Lead & Calcium EDTA, DMSA, DTPA \\
\hline Cobalt & Calcal (BAL), DMSA \\
\hline $\begin{array}{c}\text { EDTA: Ethylenediaminetetraacetic acid ; DMSA: Dimercaptosuccinic acid ; } \\
\text { DTPA: Diethylene triamine pentaacetic acid ; BAL: British anti-Lewisite }\end{array}$ \\
\hline
\end{tabular}

Table 6: Heavy metals incriminated in neurodegeneration and their antidotes.
Filgrastim showed to be not essential in children. Small 1-4 year old children were able to give up to $0.5 \times 109$ Stem Cells without mobilization (with Filgrastim) and up to 6 times more than adult when a 2-days-regimen was applied.

Erythropoietin and Statin were widely used in association with ASCT for patients suffering from stroke. It elevates the number of endothelial progenitor cells in the circulation and contributes with the recovery process $[8,9]$. The Erythropoietin group showed steadily better clinical improvement. In our next project Erythropoietin will be explored in retinal diseases, autism and dementia.

Patients' hydration one hour and more prior to bone marrow collection lead to a relative decrease in the number of progenitor cells in the extract. However the aspiration was smoother.

Stem cell collection from bone marrow is performed using bone marrow aspiration cannula. This research showed that it is a safe and non-invasive technique. The aspiration has to be done slowly at an approximate rate of $1 \mathrm{ml}$ per second to reduce the risk of hemolysis and cellular damage.

It was demonstrated that using $2 \mathrm{~mm}$ cannula resulted in a better stromal collection and therefore higher concentration of platelet derived growth factor.

It was also demonstrated that depending on the initial weight of the patient, the extracted bone marrow volume is determined. We extract $3 \mathrm{ml} / \mathrm{kg}$ body weight.

In addition, it was confirmed that higher concentration of progenitor cells were found in the posterior iliac crest comparing with other studied sites. It also has been noted that repetitive stem cell aspiration from a single site resulted in a sharp decrease in mononuclear cells count at consecutive aspiration. It is advised to change direction three times during each aspiration (Figure 9). Consequently, it is preferred to collect bone marrow from the three different locations.

As for the Buffy coat collection after separation, it was found that the manual approach gives slightly higher number of cells than in the automatized ways. The difference in cell quality was not assessed in this study.

As for culture, it was found that the suitable incubation time is for 18-24 h along with ultrafiltrate (human or xeno). This culture media is intended to enhance the growth and the differentiation of stem cells toward specific lineage. It contains sheep, rabbit or adult human specific organ extract. Those ultrafiltrates are nonpathogenic; low molecular weight (below $10 \mathrm{KDa}$ ), nanosized $(3 \mathrm{~nm})$ natural cell extract. This keeps stem cells at a high survivability rate; when as much as $95 \%$ of cells are still alive.

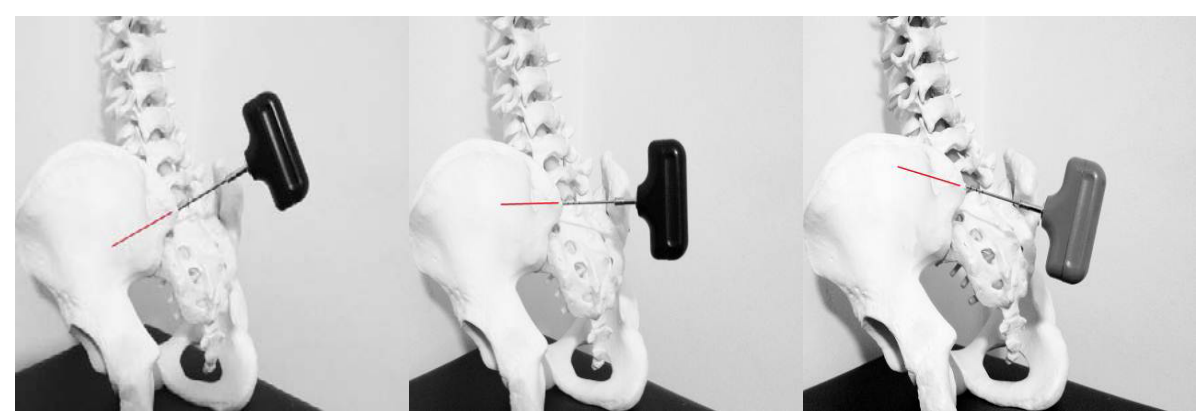

Figure 9: The 3 directions during a posterior iliac crest puncture. 
The researchers also found that the suitable incubation temperature is $20-24^{\circ} \mathrm{C}$. It reduces bacterial and fungal growth.

Researchers defined the "clustering phenomenon" happening after stem cell collection and incubation. If stem cells are maintained more than 1-2 hours without continuous agitation, they tend to agglomerate and to form a cluster which reduces their capacity to integrate in the patient's damaged circuits and makes their injection via a fine needle quiet difficult.

In addition, this paper also defines the following technical points:

The volume of drained cerebral spinal fluid-whether passively or actively- should be 7/10 the volume of final stem cell product injected.

Mannitol effect was widely explored during our study. Researchers found a significant increase in the clinical outcome of the patients treated with a Mannitol perfusion (20\%) post ASCT. It enhances the delivery of stem cells and their neurotrophic factors across the blood brain barrier [10]. The combination of those two elements leads to better clinical outcome.

For a simplified and efficient calculation we recommend that the infused volume of Mannitol should be equal to the volume of the collected bone marrow.

Heparin and Sodium Citrate were used to prevent clotting. No differences were observed in the quality of the bone marrow aspirate handling while using either of those two anticoagulants. However, a local irritation of nerve roots intrathecally was observed after using sodium citrate while researchers advise to always use it intra-operatively when patient is under general anesthesia and heparin may cause serious hemorrhagic events. Symptoms occurring after intrathecal injection of sodium citrate along with stem cells are shown in the table below (Table 7). They start seconds to minutes after the injection and last around 20-50 minutes.

\section{Post stem cell transplantation care is imperative.}

Trendelenburg position (maximum 30 degrees if no cardiac contraindication) is applied. Patients were put into this position for 1 $\mathrm{h}, 3 \mathrm{~h}$ or $10 \mathrm{~h}$. Some patients were advised to keep on this position after they were discharged for 7 to 10 days at night.

This study describes the importance of Citicoline in optimizing brain plasticity. It is a neuroprotectant and a neurorestorative drug widely effective in several stages of neurological diseases. It mobilizes endothelial progenitor cells, participates in the repairing process and the growth of neural cells. Furthermore, it protects the neurons against toxic agents, boosts active repair of damaged neurons and preserves their bioenergetic capacity leading to neurological recovery $[11,12]$.

Cerebrolysin, a neurotropic agent given intravenously or intramuscular, plays a role in neurodegenerative diseases. It can promote neuroprotection, increases neuroplasticity and neurogenesis after stem cell transplantation. It enhances neurological function by inducing the differentiation and the proliferation of endogenous progenitor cells and attracting them to assist the infused stem cells [13]

Adenosine triphosphate is an important modulator in the central nervous system via the control of excitatory glutamatergic synapses [14]. Ischemia, Parkinson, Amyotrophic lateral sclerosis, and Alzheimer groups were the most to benefit from the neuromodulation and the neuroprotection effect of this drug.

Linoleic acid and Omega 3 are found in Flax seed oil, they are $\mathrm{n}-3$ fatty acids which reduce the expression of the genes maintaining

\begin{tabular}{|c|c|}
\hline Sensory symptoms & Motor symptoms \\
\hline Burning & Lower limb spasm \\
\hline Heaviness & Hypertonicity \\
\hline Tingling & Fecal incontinence \\
\hline Parasthesia & Urinary incontinence \\
\hline
\end{tabular}

Table 7: Short term side effects of Sodium Citrate following intrathecal injection.

\begin{tabular}{|l|l|}
\hline Drug or supplement & Role \\
\hline Filgrastim & $\begin{array}{l}\text { Increases proliferation and mobilization of bone marrow } \\
\text { derived stem cells }\end{array}$ \\
\hline Erythropoietin & Elevates the number of endothelial progenitor cells \\
\hline Statin & Mobilization of endogenous progenitor cells \\
\hline Mannitol & Increases the permeability of blood-brain barrier \\
\hline Citicoline & Neuroprotection and neurorestoration \\
\hline Adenosin triphosphate & Neuromodulation and neuroprotection \\
\hline Cerebrolysin & Neuroprotection and neurogenesis \\
\hline Omega 3 & $\begin{array}{l}\text { Induces the differentiation of stem cells, maintains the } \\
\text { lipid signaling pathway }\end{array}$ \\
\hline linoleic acid & Increases angiogenesis \\
\hline Vimpocetine & Promotes oxygenation in the brain \\
\hline Huperzine A & Enhances cognitive and mental functions \\
\hline
\end{tabular}

Table 8: A summary of used drugs before and after ASCT.

stem cells in an undifferentiated state. They increase the number of endothelial progenitor cells, their migratory capacity, their functions and they reduce the harmful modulation of glycerophospholipids located at the stem cell membrane influencing lipid signaling and altering their function [15,16]. In addition Linoleic acid increases angiogenesis which is vital for stem cells to access the damaged areas [17].

Cytidine Monophosphate and Uridine Monophosphate are very promising in neurodegeneration. Those two nucleotides reduce the excitotoxicity induced by Glutamate. They increase cell survival and are beneficial for Amyotrophic Lateral Sclerosis and Parkinson patients [18].

Vimpocetine is also a cerebral metabolic activator which enhances the blood flow and promotes the appropriate usage of oxygen and glucose in the brain. In association with Vimpocetine, we gave Huperzine A which is an acetyl cholinesterase inhibitor and N-Methyl-D-aspartate receptor antagonist that provides cutting edge nutriments maximizing cognitive function and enhancing mental capacities in order to ensure additional neural support for the transplanted stem cells (Table 8) [19].

This paper described "The First Show Phenomenon" taking place hours after the therapy: patients tend to show immediate response after the injection of stem cells and they display early signs of the expected result after the completion of the neuro-regeneration.

The use of antibiotic during a 6 month period after stem cell therapy is very delicate. Researchers noticed that its use during the first months dramatically reduced the results. Third and Fourth generation cephalosporins are completely forbidden. They can cross the bloodbrain barrier and harm the transplanted cells. We consider that, during this period, stem cells in their primitive undifferentiated state seem to have bacterial behavior so they are targeted by the patient's immune system.

Many neurological diseases can be caused by the lack of oxygen supply. Recent studies have showed that some autistic features are caused by a decrease in the blood flow and oxygen in regions related to social communication and comprehension [20]. We have reported beneficial 
Citation: Abi Chahine NH, Abou Saad ES, Melki SGE (2015) How to Maximize the Success of Stem Cell Autografts for Neuroregeneration. J Stem Cell Res Ther 5: 271. doi:10.4172/2157-7633.1000271

Page 10 of 10

effect of hyperbaric chamber with ASCT for Cerebral Palsy and autism. Hyperbaric oxygen therapy can support the generation of endogenous neural stem cells enhancing the healing process of the injured region, it may be done for 1 to 2 hours daily, better as 2 independent sessions. It regulates oxygen levels in the plasma and ischemic tissues. Furthermore it helps in the mobilization of stem cells from the bone marrow and has an anti-inflammatory effect. Oxygenation increases the integration capacity of the infused neural stem cells [21-23].

As for the later papers we will discuss more the other routes of stem cells transplantations; gel foam, neurogel, Ct-guided and open surgery injections as well as the remarkable "Retrobulbar injection for Brain Stem Regeneration".

\section{Conclusion}

We concluded in this clinical research that the autologous bone marrow has the potential to treat neurological diseases thanks to its pluripotent stem cells. A series of parameters are cardinally helpful in optimizing the transplantation results and Time is on the top of those factors. The sooner a patient is treated with autologous bone marrow derived stem cells, the better are the clinical outcomes.

\section{Acknowledgment}

This research project would not have been possible without the proof reading of Saade Gibran Edmond Melki. The authors wish to express their gratitude to his support. Saade Melki, Bachelor of Biotechnology and Cell Biology from Latrobe University, and Bachelor of Science from Monash University, Australia, was abundantly helpful and offered invaluable assistance.

\section{References}

1. Jiang $Y$, Vaessen B, Lenvik T, Blackstad M, Reyes M, et al. (2002) Multipotent progenitor cells can be isolated from postnatal murine bone marrow, muscle and brain. Exp Hematol 30: 896-904. [PubMed]

2. Pacini S, Carnicelli V, Trombi L, Montali M, Fazzi R, et al. (2010) Constitutive Expression of Pluripotency-Associated Genes in Mesodermal Progenitor Cells (MPCs). PLoS One 5: e9861. [PubMed]

3. D'Ippolito G, Diabira S, Howard GA, Menei P, Roos BA, et al. (2004) Marrowisolated adult multilineage inducible (MIAMI) cells, a unique population of postnatal young and old human cells with extensive expansion and differentiation potential. J Cell Sci 117: 2971-2981. [PubMed]

4. Beltrami AP, Cesselli D, Bergamin N, Marcon P, Rigo S, et al. (2007) Multipotent cells can be generated in vitro from several adult human organs (heart, liver, and bone marrow). Blood 110: 3438-3446. [PubMed]

5. Kucia M, Reca R, Campbell FR, Zuba-Surma E, Majka M, et al. (2006) A population of very small embryonic-like (VSEL) CXCR4(+)SSEA-1(+)Oct-4+ stem cells identified in adult bone marrow. Leukemia 20: 857-869. [PubMed]

6. Nervi B, Link DC, DiPersio JF (2006) Cytokines and hematopoietic stem cell mobilization. J Cell Biochem 99: 690-705. [PubMed]

7. Nguyen YK (1994) Granulocyte colony stimulating factor. J Fla Med Assoc 81 467-469. [PubMed]

8. Yip H-K, Tsai T-H, Lin H-S, Chen S-F, Sun C-K, et al. (2011) Effect of erythropoietin on level of circulating endothelial progenitor cells and outcome in patients after acute ischemic stroke. Crit Care Lond Engl 15: R40. [PubMed]
9. Sobrino T, Blanco M, Pérez-Mato M, Rodríguez-Yáñez M, Castillo J (2012) Increased levels of circulating endothelial progenitor cells in patients with ischaemic stroke treated with statins during acute phase. Eur $\mathrm{J}$ Neurol 19 1539-1546. [PubMed]

10. Okuma Y, Wang F, Toyoshima A, Kameda M, Hishikawa T, et al. (2013) Mannito enhances therapeutic effects of intra-arterial transplantation of mesenchymal stem cells into the brain after traumatic brain injury. Neurosci Lett 554: 156161. [PubMed]

11. Dávalos A, Secades J (2011) Citicoline Preclinical and Clinical Update 20092010. Stroke 42: S36-39. [PubMed]

12. Gutiérrez-Fernández M, Fuentes B, Rodríguez-Frutos B, Ramos-Cejudo J Vallejo-Cremades MT, et al. (2012) Trophic factors and cell therapy to stimulate brain repair after ischaemic stroke. J Cell Mol Med 16: 2280-2290. [PubMed]

13. Zhang C, Chopp M, Cui Y, Wang L, Zhang R, et al. (2010) Cerebrolysin enhances neurogenesis in the ischemic brain and improves functional outcome after stroke. J Neurosci Res 88: 3275-3281. [PubMed]

14. Gomes CV, Kaster MP, Tomé AR, Agostinho PM, Cunha RA (2011) Adenosine receptors and brain diseases: Neuroprotection and neurodegeneration. Biochim Biophys Acta 1808: 1380-1399. [PubMed]

15. Hu X, Zhang F, Leak RK, Zhang W, Iwai M, et al. (2013) Transgenic overproduction of omega-3 polyunsaturated fatty acids provides neuroprotection and enhances endogenous neurogenesis after stroke. Curr Mol Med 13: 14651473. [PubMed]

16. Devaraj S, Chien A, Rao B, Chen X, Jialal I (2013) Modulation of endothelia progenitor cell number and function with n-3 polyunsaturated fatty acids. Atherosclerosis 228: 94-97. [PubMed]

17. Smith AN, Muffley LA, Bell AN, Numhom S, Hocking AM (2012) Unsaturated fatty acids induce mesenchymal stem cells to increase secretion of angiogenic mediators. J Cell Physiol 227: 3225-3233. [PubMed]

18. http://file.scirp.org/Html/14-2400055_5538.htm

19. Ma T, Gong K, Yan Y, Zhang L, Tang P, et al. (2013) Huperzine A promotes hippocampal neurogenesis in vitro and in vivo. Brain Res 1506: 35-43. [PubMed]

20. Mukherjee A, Raison M, Sahni T, Arya A, Lambert J, et al. (2014) Intensive rehabilitation combined with $\mathrm{HBO} 2$ therapy in children with cerebral palsy: a controlled longitudinal study. Undersea Hyperb Med J Undersea Hyperb Med Soc Inc 41: 77-85. [PubMed]

21. Lee Y-S, Chio C-C, Chang C-P, Wang L-C, Chiang P-M, et al. (2013) Long course hyperbaric oxygen stimulates neurogenesis and attenuates inflammation after ischemic stroke. Mediators Inflamm 2013: 512978. [PubMed]

22. Zádori A, Agoston VA, Demeter K, Hádinger N, Várady L, et al. (2011) Surviva and differentiation of neuroectodermal cells with stem cell properties at different oxygen levels. Exp Neurol 227: 136-148. [PubMed]

23. Thom SR, Bhopale VM, Velazquez OC, Goldstein LJ, Thom LH, et al. (2006) Stem cell mobilization by hyperbaric oxygen. Am J Physiol Heart Circ Physiol 290: H1378-1386. [PubMed] 